\title{
Successful ablation of ventricular tachycardia with a novel multipolar high-density mapping catheter
}

\author{
Tardu Özkartal ${ }^{1}$, S. Andreas Müller-Burri ${ }^{2}$, Corinna B. Brunckhorst ${ }^{1}$, Laurent M. Haegeli ${ }^{1}$ \\ ${ }^{1}$ Department of Cardiology, University Heart Center Zurich, Switzerland \\ ${ }^{2}$ Department of Cardiology, Stadtspital Triemli, Zurich, Switzerland
}

We report a case of a 72-year-old male patient with coronary artery disease who was referred to our institution for repeated ablation of sustained ventricular tachycardia (VT). In 1992 and 2002, the patient suffered an anterior myocardial infarction which was revascularized with coronary artery bypass grafts in 2002. As his left systolic ventricular function was severely impaired (ejection fraction of $24 \%$ ), he received an implantable cardioverter defibrillator (ICD) for primary prevention of sudden cardiac death in 2003. He also suffers from diabetes mellitus, obstructive sleep apnea, peripheral vascular disease, and chronic obstructive pulmonary disease. Furthermore, he was on optimal pharmacologic therapy for heart failure for many years, including beta-blocker (bisoprolol $10 \mathrm{mg}$ ),

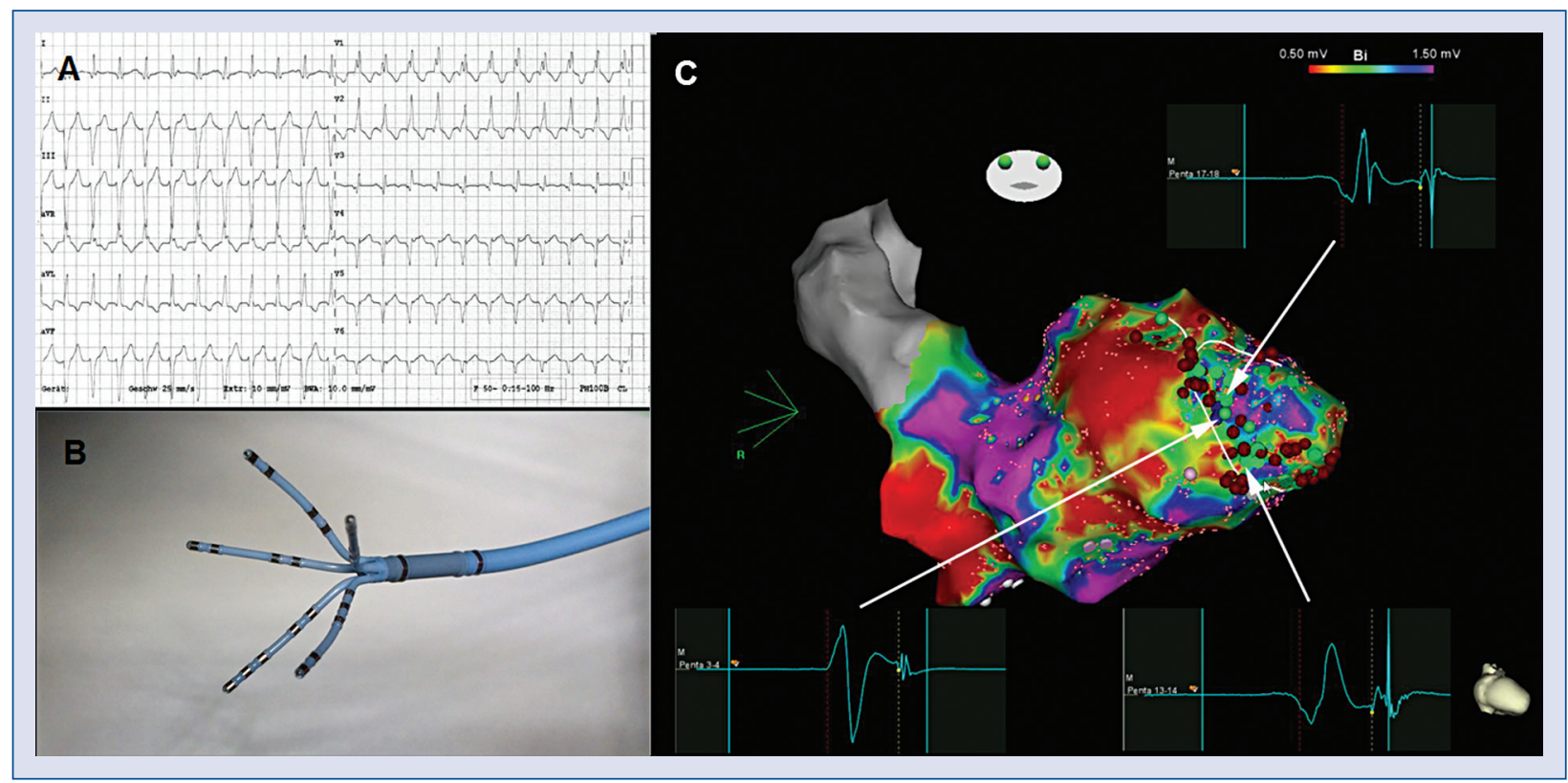

Figure 1. A. 12-lead electrocardiogram of the clinical slow ventricular tachycardia with negative QRS in the inferior leads and in lead V4-V6, as well as positive QRS in lead V1-V3 suggesting an inferolateral midventricular origin; B. Multipolar high-density mapping PentaRay ${ }^{\circledR}$ catheter (Biosense Webster, Diamond Bar, CA) with 5 soft spines consisting of 20 poles (1 $\mathrm{mm}$ electrode dimension, 2-6-2 $\mathrm{mm}$ spacing size), covering a diameter of $3.5 \mathrm{~cm}$, corresponding to an area of over $7 \mathrm{~cm}^{2}$; C. Three-dimensional electroanatomic and bipolar voltage map showing areas of low voltage $<0.5 \mathrm{mV}$ representing scar tissue (red areas), as well as point-by-point ablation sites of the critical sites of the reentrant circuit (brown points). Three intracardiac electrograms showing late potentials are also depicted.

Address for correspondence: PD Dr. med. Laurent M. Haegeli, Senior Staff Cardiology, Head of Electrophysiology Lab, University Heart Center Zurich, Rämistrasse 100, 8091 Zürich, Switzerland, tel: +41 4425511 11, fax: +41 442554401 , e-mail: laurent.haegeli@usz.ch

Received: 16.03.2016 Accepted: 24.05.2016 


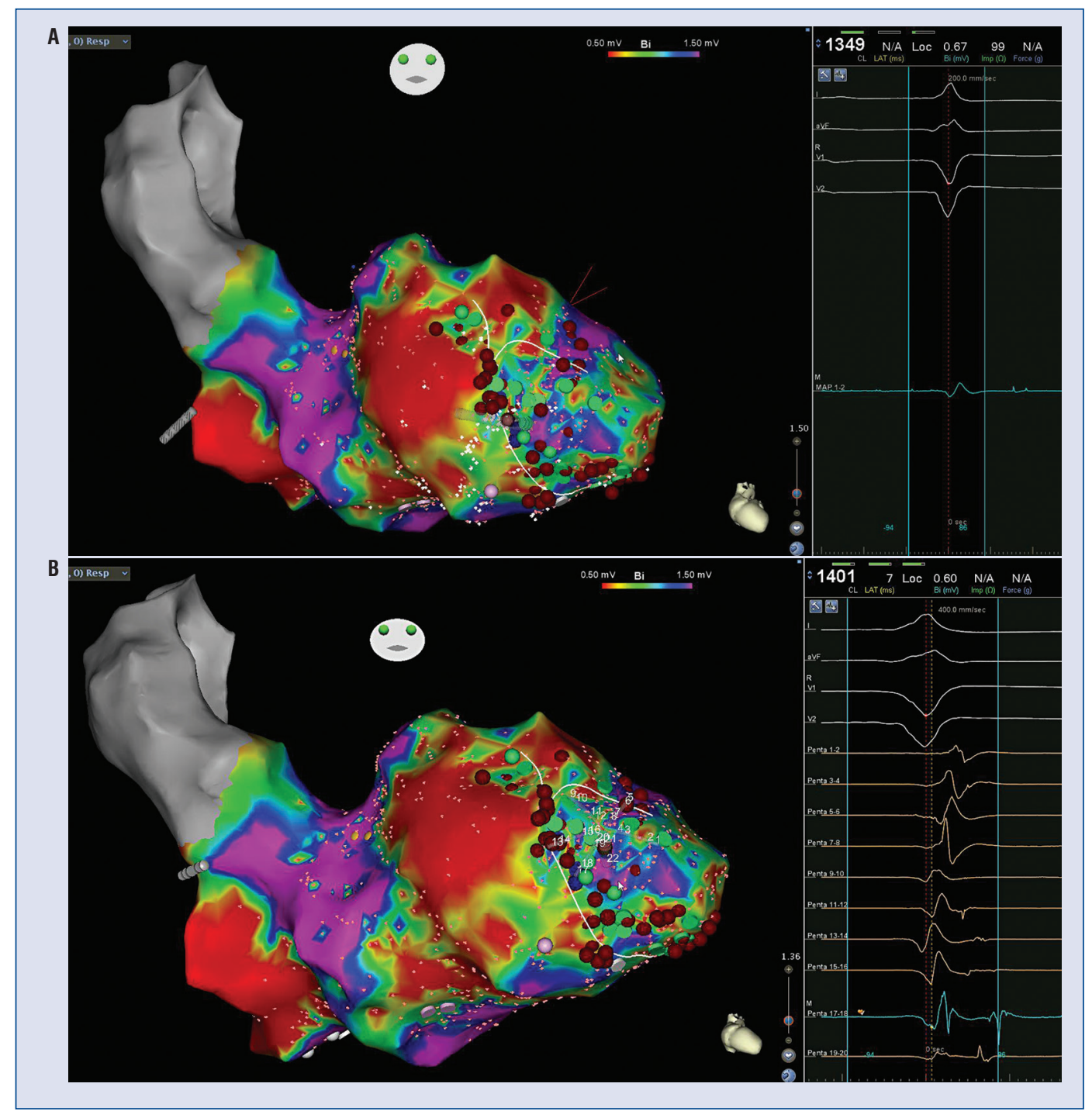

Figure 2. Three-dimensional electroanatomic and bipolar voltage maps with intracardiac electrograms showing late potentials recorded from the same site with the conventional $3.5 \mathrm{~mm}$ tip ablation catheter on Panel $\mathbf{A}$ and with the multipolar high-density mapping PentaRay ${ }^{\circledR}$ catheter (Biosense Webster, Diamond Bar, CA) with 5 soft spines consisting of 20 poles on Panel B.

angiotensin converting enzyme-inhibitor (ramipril $2.5 \mathrm{mg}$ ), aldosterone inhibitor (aldactone $12.5 \mathrm{mg}$ ) and diuretics (torasemid $10 \mathrm{mg}$ ).

In 2015 , the patient was hospitalized due to an electrical storm with recurrent sustained VTs requiring multiple shocks from his ICD. He underwent radiofrequency catheter ablation. In addition to his medication with a beta-blocker, an antiarrhythmic drug regimen with amiodarone was initiated to suppress further ventricular tachyarrhythmias [1].

Three months later he was hospitalized again because of acute chest pain. A 12-lead electrocar- diogram (ECG) showed a sustained slow VT with a rate of $134 \mathrm{bpm}$, corresponding to a tachycardia cycle length of $448 \mathrm{~ms}$ (Fig. 1A). Due to the therapy with amiodarone, the VT was slow and below the programmed cutoff rate of $176 \mathrm{bpm}$ for VT detection of the ICD [2]. Therefore, no antitachycardia pacing or defibrillation of the ICD occurred. The ECG of the VT documented a negative QRS in the inferior leads and in lead V4-V6, as well as a positive QRS in lead V1-V3 suggesting an inferolateral midventricular origin of the VT [3]. The VT could successfully be terminated in the emergency room with manual overdrive-pacing via 
the ICD. A coronary angiography showed patent bypass grafts and excluded progression of coronary artery disease. After reprogramming the ICD to a lower VT detection zone, as well as increasing the number and length of anti-tachycardia pacing (ATP), the slow VTs were adequately detected and successfully terminated after several ATP attempts. Since the patient suffered from recurrent symptomatic VTs despite ICD reprogramming, he was referred for catheter ablation. At the beginning of the electrophysiological study, the clinical VT could easily be induced showing the clinical QRS morphology. In general anesthesia, a bipolar voltage map (Fig. 1C) of the left ventricle with a novel multi-polar high-density mapping PENTARAY ${ }^{\circledast}$ catheter (Biosense Webster, Diamond Bar, CA) was acquired in sinus rhythm (Fig. 1B) via transseptal and retrograde catheter access sequentially. This high-density mapping catheter consists of 20 poles ( $1 \mathrm{~mm}$ electrode dimension, 2-6-2 $\mathrm{mm}$ spacing size), arranged in 5 soft spines covering a diameter of $3.5 \mathrm{~cm}$. Together with a new software (CONFIDENSE ${ }^{\mathrm{TM}}$ module) of the electrophysiology navigation system CARTO 3 (Biosense Webster, Diamond Bar, CA), it is able to automatically collect electrode locations and electrical information (activation and voltage) of the tissue in contact in up to 10 different locations simultaneously. With this novel mapping catheter we were able to collect local voltages of over 2,500 different locations from the left ventricular endocardium within a short period of time. Areas of low voltage $<0.5 \mathrm{mV}$ were considered dense scar and were marked in red in the voltage map. Two different areas of dense scar tissue could be identified - one inferolateral midventricular area (as suggested by the clinical VT) and one at the apex. Surviving myocytes within the dense scar lead to a zone of slow conduction and, combined with areas of anatomic or functional conduction block, give rise to electric re-entry circuits [4-9]. At the border zones of these areas, fractionated and late potentials were identified by this novel multipolar high-density mapping catheter (Fig. 1C), while no abnormal signals were seen with the conventional $3.5 \mathrm{~mm}$ tip ablation catheter (Fig. 2). Ablation was applied point-by-point in these distinct areas representing a critical pathway of the ventricular reentrant circuit (brown points in Fig. 1C). At the end of the procedure the clinical VT could not be induced by programmed stimulation with up to 4 extrastimuli. The patient could be discharged the following day and remained free from ventricular tachyarrhythmias.

\section{Conflict of interest: None declared}

\section{References}

1. Connolly SJ, Dorian P, Roberts RS et al. Optimal Pharmacological Therapy in Cardioverter Defibrillator Patients (OPTIC) Investigators. Comparison of beta-blockers, amiodarone plus beta-blockers, or sotalol for prevention of shocks from implantable cardioverter defibrillators: the OPTIC Study: A randomized trial. JAMA, 2006; 295: 165-171. doi: 10.1001/jama.295.2.165.

2. Mitchell LB, Wyse DG, Gillis AM, Duff HJ. Electropharmacology of amiodarone therapy initiation. Time courses of onset of electrophysiologic and antiarrhythmic effects. Circulation, 1989; 80: 34-42.

3. Benito B, Josephson ME. Ventricular tachycardia in coronary artery disease. Rev Esp Cardiol (Engl Ed), 2012; 65: 939-955.

4. Stevenson WG, Khan H, Sager P et al. Identification of reentry circuit sites during catheter mapping and radiofrequency ablation of ventricular tachycardia late after myocardial infarction. Circulation, 1993; 88 (4 Part 1): 1647-1670

5. Berte B, Relan J, Sacher F et al. Impact of electrode type on mapping of scar-related VT. J Cardiovasc Electrophysiol, 2015. doi: 10.1111/jce.12761. [Epub ahead of print]

6. Luther V, Qureshi N, Kanagaratnam P, Boon Lim P. Automated activation and pace-mapping to guide ablation within the outflow tract. J Cardiovasc Electrophysiol, 2016; 27: 127-128. doi: 10.1111/jce.12743.

7. Sacher F, Lim HS, Derval N et al. Substrate mapping and ablation for ventricular tachycardia: The LAVA approach. J Cardiovasc Electrophysiol, 2015; 26: 464-471. doi: 10.1111/jce.12565.

8. Akdis D, Saguner AM, Brunckhorst CB, Duru F, Haegeli LM. Successful epicardial ablation of ventricular tachycardia in a patient with arrhythmogenic right ventricular cardiomyopathy. Int J Cardiol, 2016; 211: 22-24. doi: 10.1016/j.ijcard.2016.02.119.

9. Haegeli LM, Della Bella P, Brunckhorst CB. Management of a patient with electrical storm: role of epicardial catheter ablation. Circulation, 2016; 133: 672-676. doi: 10.1161/CIRCULATIONAHA.115.016336. 